\title{
Artesunate + amodiaquine versus artemether-lumefantrine for the treatment of uncomplicated Plasmodium falciparum malaria in the Colombian Pacific region: a noninferiority trial
}

\author{
Fernando De la Hoz Restrepo ${ }^{[1]}$, Alexandra Porras Ramírez ${ }^{[1]}$, Alejandro Rico Mendoza ${ }^{[1]}$, \\ Freddy Córdoba ${ }^{[2]}$ and Diana Patricia Rojas ${ }^{[3]}$
}

[1]. School of Medicine, National University of Colombia, Bogota, DC, Colombia. [2]. Vector-transmitted Diseases Prevention and Control Program Coordinator, Health Administrative Department (Dasalud), Chocó, Colombia. [3]. Dengue Surveillance, National Institute of Health, Bogotá, DC, Colombia.

\begin{abstract}
Introduction: In Colombia, there are no published studies for the treatment of uncomplicated Plasmodium falciparum malaria comparing artemisinin combination therapies. Hence, it is intended to demonstrate the non-inferior efficacy/safety profiles of artesunate + amodiaquine versus artemetherlumefantrine treatments. Methods: A randomized, controlled, open-label, noninferiority $(\Delta \leq 5 \%)$ clinical trial was performed in adults with uncomplicated P. falciparum malaria using the 28-day World Health Organization validated design/definitions. Patients were randomized 1:1 to either oral artesunate + amodiaquine or artemether-lumefantrine. The primary efficacy endpoint: adequate clinical and parasitological response; secondary endpoints: - treatment failures defined per the World Health Organization. Safety: assessed through adverse events. Results: A total of 105 patients was included in each group: zero censored observations. Mean $(95 \% \mathrm{Cl}$ - Confidence interval) adequate clinical and parasitological response rates: $100 \%$ for artesunate + amodiaquine and $99 \%$ for artemether-lumefantrine; the noninferiority criteria was met $(\Delta=1.7 \%)$. There was one late parasitological therapeutic failure ( $1 \%$; artemether-lumefantrine group), typified by polymerase chain reaction as the MAD20 MSP1 allele. The fever clearance time (artesunate + amodiaquine group) was significantly shorter $(p=0.002)$. Respectively, abdominal pain for artesunate + amodiaquine and artemether-lumefantrine was $1.9 \%$ and $3.8 \%$ at baseline $(p=0.68)$ and $1 \%$ and $13.3 \%$ after treatment $(p<0.001)$. Conclusions: Uncomplicated $P$. falciparum malaria treatment with artesunate + amodiaquine is noninferior to the artemetherlumefantrine standard treatment. The efficacy/safety profiles grant further studies in this and similar populations.
\end{abstract}

Keywords: Artesunate-amodiaquine combination. Artemether-lumefantrine combination. Efficacy. Safety. Malaria-falciparum. Colombia.

\section{INTRODUCTION}

Malaria is a widespread tropical parasitic disease characterized by a large worldwide morbidity burden. In 2009, estimates of 225 million malaria cases (781,000 deaths) worldwide, 1.1 million cases in the Americas (1,300 deaths), and 79,252 cases in Colombia (12 deaths) were reported by the World Health Organization (WHO ${ }^{1}$. Plasmodium falciparum accounts for $25 \%$ of the malaria cases in Colombia ${ }^{1}$; yet, this percentage increases to $75 \%$ in the Pacific region. This phenomenon is partially explained by the high (26.4\%) prevalence of hemoglobinopathies and Duffy-negative (Fy-) phenotypes in the predominantly African-descent population ${ }^{2}$. As a consequence, more than half of the national $P$. falciparum cases are reported in this region ${ }^{3}$. Figure 1 presents selected geographic, demographic, and malaria statistics for Quibdó and Tadó, two municipalities in the Chocó department, located in the Colombian Pacific region ${ }^{1,4-6}$.

Early antimalarial measures included Anophelinae subfamily vector control and the folkloric use of quinine- and artemisinin-based monotherapy ${ }^{7}$. Reports of in vitro and in vivo P. falciparum resistance to chloroquine (CQ) in South America, including the Colombian Pacific region, have been published ${ }^{8-10}$. Due to the increasing worldwide CQ resistance reports, the most current antimalarial

Address to: Dr. Alexandra Porras Ramirez. 45-67, 44 St., Camilo Torres Unit, Module 2, C Block, Office 501, Bogota, DC, Colombia.

Phone: $571316-5683$

e-mail: porras.alexandra@gmail.com

Received in 24/11/2011

Accepted in 04/05/2012 treatment recommended by WHO is combination therapy with two or more blood schizonticidal drugs. As opposed to monotherapy, this approach improves treatment outcome and decreases de novo resistance. Nonetheless, it increases treatment-related adverse events and costs ${ }^{11}$.

Artemisinin derivatives - such as arthemeter, artemotil, artesunate, and dihydroartemisinin - are active against all four Plasmodium species, are generally well tolerated, and have been shown to reduce the transmissibility of malaria by decreasing gametocyte carriage ${ }^{11}$. Four artemisinin combination therapies (ACT) are currently recommended by $\mathrm{WHO}^{11}$ : artemether-lumefantrine $(\mathrm{AL})$, artesunate + amodiaquine $(A S+A Q)$, artesunate + mefloquine $(A S+M Q)$, and artesunate + sulfadoxine-pyrimetamine (AS+SP). The Colombian Ministry of Social Protection (CMSP; former Ministry of Health) implemented WHO recommendation of $A C T$ with the use of $A L$ as the first-line standard of care for confirmed uncomplicated $P$. falciparum malaria cases. In 2009, 1.28 million doses of AL were administered in Colombia ${ }^{1}$.

In vivo resistance to artemisinin derivatives has only been reported in Southeastern Asia ${ }^{12,13}$, not in Africa or the Americas. Treatment with $A S+A Q$ has been used in Africa for the treatment of $P$. falciparum malaria with very good efficacy, safety, and costeffectiveness profiles ${ }^{14,15}$. This combination has been previously studied in Colombia ${ }^{16}$, but to date, no reports comparing its efficacy with other ACT have been published for this country. This clinical trial was designed to test the noninferiority efficacy profile of $A S+A Q$ versus $A L$ standard therapy for the treatment of patients with uncomplicated P. falciparum malaria in the municipalities of Quibdó and Tadó, both in the Chocó department located in the Colombian Pacific region. The safety profiles of both treatments were also compared. 


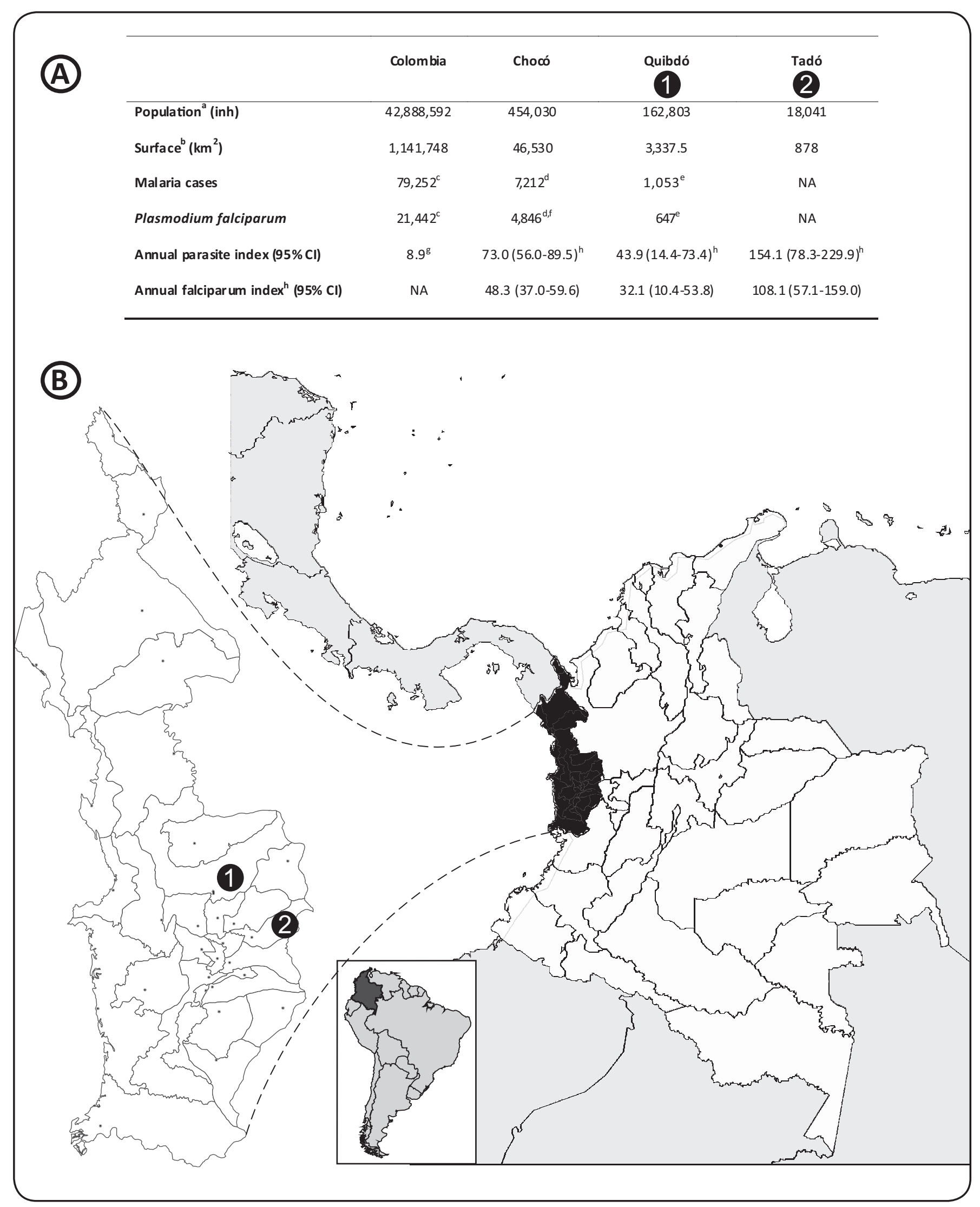

FIGURE 1 - A: Selected geographic, demographic, and malaria data in Colombia. B: Geographic situation of the Colombian Pacific regions of Quibdó and Tadó.

${ }^{a}$ Adjusted. ${ }^{b}$ From Wikipedia. Available from: www.wikipedia.com. ${ }^{C}$ In 2009. ${ }^{d}$ In 2008. ${ }^{\mathrm{e}}$ In 2001 . ${ }^{\mathrm{f}}$ Malaria cases were calculated multiplying the percentage of Plasmodium falciparum cases $(67.2 \%)$ by the total number of malaria cases $(7,212)$. ${ }^{g}$ In the 1994-2004 period. ${ }^{\mathrm{h}}$ In the 1998-2006 period. inh.: inhabitants; NA: not available in the sources reviewed; $\mathbf{C l}$ : confidence interval. 


\section{METHODS}

\section{Design}

This was a randomized, controlled, open-label clinical trial using the WHO-validated design for noninferiority efficacy in uncomplicated P. falciparum malaria ${ }^{17}$, with the additional recommendations by the Pan-American Health Organization (PAHO) ${ }^{18}$. Even though this was an open-label clinical trial, blinding was kept for the staff performing patient follow-up and for the laboratory technicians reading the thick blood smears, as recommended by the United States Food and Drug Administration (FDA) protocol ${ }^{19}$.

A sample size of 210 subjects (105 in each treatment arm) was calculated based on an estimated $95 \%$ efficacy for both treatments, a $5 \%$ (range $1 \%-11 \%$ ) proportion of failures to treatment, a two-sided $5 \%$ alpha error, an $80 \%$ statistical power, and a $5 \%$ estimated loss of patients to follow-up.

\section{Patients}

Patients were eligible if they were 18 years of age or older, had an axillary temperature $>37.5$ 으 $\mathrm{C}$ or history of fever in the absence of another cause of fever in the $48 \mathrm{~h}$ previous to the initial study visit (day 0), and a P. falciparum monoinfection with 250 to 100,000 asexual parasites/ $\mu \mathrm{L}$, confirmed by microscopy.

Patients were excluded if they were unable to swallow oral medication, presented more than 2 vomiting episodes in the $24 \mathrm{~h}$ previous to day 0 , had a history of hypersensitivity to any of the protocol drugs, or presented severe chronic hematologic, hepatic, or renal illness, determined by the physician in the initial visit. WHO-defined clinical manifestations of severe malaria (ie, prostration, impaired consciousness, respiratory distress, multiple convulsions, circulatory collapse, abnormal bleeding, jaundice, hemoglobinuria) precluded the participation in this study, as well as women who tested positive in a urine pregnancy test.

All eligible patients were included once their written informed consent was obtained, and they were randomized 1:1 to either treatment group through a random-numbers table. A monthly interim analysis was performed by an external Data Safety Monitoring Board to assess the therapeutic failures as defined by $\mathrm{WHO}^{17}$ and ensure an ethical conduction of the study. The Board would also terminate the study if the efficacy of any study drug was below $90 \%$ after consecutively treating 60 patients.

\section{Treatments}

Patients were randomized to either treatment group receiving the fixed-dose oral ACT. The AS+AQ (Coarsucam ${ }^{\circledR}$; SANOFI, France; AS 540mg + AQ 200mg per tablet) schedule consisted of 2 tablets on Day 0 , followed by two additional 2-tablet doses on days 1 and 2. The AL (Coartem ${ }^{\circledast}$; Novartis Pharma AG, Switzerland; artemether $80 \mathrm{mg}$ + lumefantrine $480 \mathrm{mg}$ per tablet) schedule consisted of 4 tablets on Day 0 , followed by five additional 4-tablet doses at 8, 24, 36, 48, and $60 \mathrm{~h}$ after the initial dose.

All of the drug doses were administered by the research staff at the health care facility on an outpatient basis if the patient was considered suitable (ie, mobilization to and from the health care facility was possible), or the research staff provided the study patients with the remaining doses per domiciliary visits. A number of patients who could not be closely monitored by the previously mentioned approaches were managed on an inpatient basis to ensure the administration of all the treatment doses. After the drug administration, patients were observed during $30 \mathrm{~min}$ for adverse events or vomiting. Patients who presented vomiting within this period were then provided with another dose of the study drugs and were observed for 30 additional minutes. If a second vomiting episode occurred, the patient was excluded from the study and initiated on standard parenteral therapy for severe malaria, as defined by the CMSP guidelines.

Concomitant treatment with acetaminophen was provided to patients presenting axillary temperature $\geq 39$ 으. Follow-up visits and procedures were scheduled per WHO protocol (ie, on days 1, 2, 3, 7, $14,21$, and 28$)^{17}$. Nonetheless, patients were instructed to visit the health care facilities if they felt any worrisome discomfort or symptom (including, but not limited to fever, malaise, headache, and vomiting). In case of a first-line therapeutic failure as defined by $\mathrm{WHO}^{17}$, an oral second-line therapeutic combination of quinine $(10 \mathrm{mg} / \mathrm{kg}$ every day for 7 days) and primaquine (single 45-mg dose) was administered, and a polymerase chain reaction (PCR) was performed to typify the MSP1 gene alleles and distinguish true therapeutic failures from reinfections.

\section{Endpoints}

The primary efficacy endpoint was the adequate clinical and parasitological response (ACPR), defined as absence of parasitemia on day 28 , irrespective of axillary temperature, in patients who did not previously meet any of the criteria of early treatment failure, late clinical failure or late parasitological failure.

Secondary efficacy endpoints included treatment failures as defined by WHO protoco ${ }^{17}$. Early treatment failure (ETF) was defined as severe malaria on days 1, 2, or 3 in the presence of parasitemia; parasitemia on day 2 higher than on day 0 , irrespective of axillary temperature; or parasitemia on day 3 with axillary temperature $\geq 37.5$ ㅇ $\mathrm{C}$ or $\geq 25 \%$ of parasite count on day 0 . Late treatment failure was further divided into clinical or parasitological. Late clinical treatment failure (LCTF) included patients who did not previously meet any of the ETF criteria and had parasitemia on any day between days 4 and 28 with either severe malaria, or axillary temperature $\geq 37.5 \circ \mathrm{C}$ (or history of fever), or parasitological failures. Patients who did not meet ETF and LCTF criteria who had parasitemia on any day between days 7 and 28 and axillary temperature $<37.5 \circ \mathrm{C}$ were considered as having a late parasitological treatment failure (LPTF). In order to determine if a therapeutic failure was due to the drug administered and not due to a reinfection, all three failure rates (ie, ETF, LCTF, LPTF) were analyzed as PCR-unadjusted (crude) and PCR-adjusted.

Other efficacy measurements included mean parasitemia on Day 1 and mean parasite, fever, and gametocyte clearance times. An exploratory endpoint was the analysis of possible risk factors for therapeutic failures (ie, age, previous antimalarial therapy, and initial parasitemia). Safety was assessed through patient spontaneous report of adverse events and serious adverse events at follow-up or at any unscheduled visits.

\section{Statistical analysis}

The per-protocol population data values were entered in duplicate in a WHO-standardized ${ }^{17}$ Excel spreadsheet (The Microsoft Corporation; Redmond, WA). Noninferiority of AS+AQ versus AL was 
assumed if the lower limit of the $95 \%$ confidence interval (CI) for the treatment difference was greater than $5 \%$ for the mean parasitological cure rate at day 28 or any of the secondary efficacy endpoints. This $5 \%$ noninferiority margin $(\Delta)$ approximates the treatment difference in parasitological cure rates at day 28 that might be expected from discrepancies in disease treatment ${ }^{20,21}$. Secondary efficacy end points were summarized through descriptive statistics (ie, percentages, means, geometric means for parasitemia counts, standard deviations [SDs], and 95\% Cls). The Kaplan-Meier analysis method was used to calculate the mean time to failure and to estimate failure rates. The two-sided $p$ values for the comparisons between the two groups were calculated using GraphPad (GraphPad Software, Inc.; La Jolla, CA). The statistical tests applied to the secondary efficacy endpoints were the two-tailed Fisher exact test for the comparison of two proportions and the Student $t$ test with 208 degrees of freedom for the comparison of two means.

\section{Ethical considerations}

After thorough considerations and reviews, the Ethics Committee of the National University of Colombia School of Medicine approved the study protocol, which was registered under the number CE-095. The National Institute of Drug and Food Surveillance (INVIMA) also reviewed and approved the study protocol (under the code \# 626421). Patient confidentiality was kept and the trial was conducted according to the ethical principles stated in the sixth revision of the Declaration of Helsinski ${ }^{22}$ and the applicable Colombian laws and regulations.

\section{RESULTS}

The target recruitment of 210 patients was achieved from August 2008 to September 2009, without deaths, censored observations, or losses to follow-up. Hence, the per-protocol analysis set is the same as the KaplanMeier analysis set. There were no protocol violations, and the Data Safety Monitoring Board found no reasons to interrupt the study during interim analyses.

Table 1 shows the baseline demographic and clinical characteristics of the study population. The mean ages for both study groups were similar, and the male-tofemale ratio was well balanced. In both treatment groups, more than $80 \%$ of the population was of African descent, most patients came from the municipality of Tadó, and more than $90 \%$ was affiliated with the social security system. Globally, 126 patients reported a previous episode of malaria, 18 of which occurred in the previous year. Eighty-four patients received either study treatment in an inpatient basis during the trial. Overall, the duration of malaria symptoms ranged from 4 to 17 days, with a mean (SD) of 4.2 (3.1) days for the AS+AQ group and 4.5 (2.6) days for the AL group ( $p=0.45)$.
TABLE 1 - Baseline demographic and clinical characteristics.

\begin{tabular}{|c|c|c|c|c|c|}
\hline & \multicolumn{2}{|c|}{$A S+A Q(n=105)$} & \multicolumn{2}{|c|}{$A L(n=105)$} & \multirow[b]{2}{*}{$P$ value } \\
\hline & $\mathrm{n}$ & $\%$ & $\mathbf{n}$ & $\%$ & \\
\hline Age, years, mean (SD) & 38.4 & 14.5 & 36.7 & 13.4 & 0.40 \\
\hline Males, n (\%) & 59 & 56.2 & 52 & 49.5 & 0.41 \\
\hline Body weight, kg, mean (SD) & 63.9 & 8.0 & 65.3 & 6.6 & 0.16 \\
\hline Height, m, mean (SD) & 1.61 & 0.05 & 1.62 & 0.06 & 0.19 \\
\hline Body mass index, kg/m², mean (SD) & 24.5 & 2.4 & 24.8 & 2.6 & 0.39 \\
\hline African descent ethnicity, n (\%) & 89 & 84.8 & 95 & 90.6 & 0.30 \\
\hline \multicolumn{6}{|l|}{ Municipality, n (\%) } \\
\hline Tadó & 84 & 80.0 & 80 & 76.2 & 0.62 \\
\hline Quibdó & 21 & 20.0 & 25 & 23.8 & - \\
\hline Social security affiliation, $\mathrm{n}(\%)$ & 97 & 92.3 & 95 & 90.6 & 0.81 \\
\hline \multicolumn{6}{|l|}{ Previous history, n (\%) } \\
\hline malaria & 68 & 64.8 & 58 & 55.2 & 0.20 \\
\hline fever & 105 & 100.0 & 105 & 100.0 & $>0.99$ \\
\hline Malaria evolution time, days, mean (SD) & 4.2 & 3.1 & 4.5 & 2.6 & 0.45 \\
\hline \multicolumn{6}{|l|}{ Symptoms at inclusion (day 0), n (\%) } \\
\hline fever & 105 & 100.0 & 105 & 100.0 & $>0.99$ \\
\hline cephalea & 105 & 100.0 & 105 & 100.0 & $>0.99$ \\
\hline shivers & 103 & 98.1 & 105 & 100.0 & 0.50 \\
\hline diaphoresis & 103 & 98.1 & 105 & 100.0 & 0.50 \\
\hline myalgias & 103 & 98.1 & 105 & 100.0 & 0.50 \\
\hline abdominal pain & 2 & 1.9 & 4 & 3.8 & 0.68 \\
\hline vomiting & 2 & 1.9 & 4 & 3.8 & 0.68 \\
\hline Axillary temperature, ${ }^{\circ} \mathrm{C}$, mean (SD) & 38.3 & 0.5 & 38.2 & 0.4 & 0.53 \\
\hline Parasitemia, asexual parasites/iL, mean (SD) & 6,887 & 9,464 & 4,693 & 6,225 & 0.048 \\
\hline Patients with gametocytes, $\mathrm{n}(\%)$ & 2 & 1.9 & 14 & 13.3 & 0.003 \\
\hline
\end{tabular}

AS: artesunate; AQ: amodiaquine; AL: artemether-lumefantrine; SD: standard deviation.

TABLE 2 - Secondary efficacy results.

\begin{tabular}{|c|c|c|c|c|c|}
\hline & \multicolumn{2}{|c|}{$A S+A Q(n=105)$} & \multicolumn{2}{|c|}{$A L(n=105)$} & \multirow[b]{2}{*}{$P$ value } \\
\hline & $\mathbf{n}$ & $\%$ & $\mathrm{n}$ & $\%$ & \\
\hline Parasite clearance time, days & 1 & 1.2 & 2 & 3.2 & 0.23 \\
\hline Fever clearance time, hours & 8 & 12.3 & 48 & 32.1 & 0.002 \\
\hline \multicolumn{6}{|l|}{ Therapeutic failure, n (\%) } \\
\hline early & 0 & 0.0 & 0 & 0.0 & $>0.99$ \\
\hline late clinical & 0 & 0.0 & 0 & 0.0 & $>0.99$ \\
\hline late parasitological & 0 & 0.0 & 1 & $1.0^{\mathrm{a}}$ & $>0.99$ \\
\hline Time to negative gametocytemia, days & 2 & 1.3 & 4 & 4.5 & $<0.001$ \\
\hline \multicolumn{6}{|l|}{ Parasitemia ${ }^{b, c}$ asexual parasites/iL } \\
\hline day 1 & 181.8 & 247.5 & 182.1 & 668.8 & 0.76 \\
\hline \multicolumn{6}{|l|}{ Temperature, $\stackrel{\circ}{-C}$} \\
\hline day 1 & 37.2 & 0.5 & 37.0 & 0.4 & 0.05 \\
\hline day 2 & 37.1 & 0.5 & 37.2 & 0.4 & 0.05 \\
\hline day 3 & 37.0 & 0.5 & 37.0 & 0.4 & 0.05 \\
\hline day 7 & 37.0 & 0.5 & 37.2 & 0.4 & 0.05 \\
\hline day 14 & 36.8 & 0.5 & 37.2 & 0.4 & 0.05 \\
\hline day 21 & 37.1 & 0.5 & 37.0 & 0.4 & 0.05 \\
\hline day 28 & 37.0 & 0.5 & 37.0 & 0.4 & 0.05 \\
\hline
\end{tabular}

All values are mean (SD), unless otherwise specified. ${ }^{a}$ Genotyped through PCR as the MAD20 MSP1 allele. ${ }^{b}$ No asexual parasites were reported in either group on days 2, 3, 7, 14, 21, and $28 .{ }^{\mathrm{C}}$ Geometric means and SDs are reported for this variable. AS: artesunate; AQ: amodiaquine; AL: artemether-lumefantrine; SD: standard deviation. 
In both study groups, all patients presented with fever and cephalea with more than $98 \%$ presenting with diaphoresis and myalgia. Baseline abdominal pain and vomiting were reported in less than $4 \%$ of patients in each group (Table 1).

When compared to AL, AS+AQ had a noninferiority margin of $1.7 \%$. The primary efficacy endpoint, ie, ACPR, was not significantly different ( $p>0.99$ ) for AS+AQ (100\%; 95\% Cl 96.6\%-100\%) when compared to $\mathrm{AL}(99 \% ; 95 \% \mathrm{Cl} 94.8 \%-100 \%)$. All the secondary efficacy variables are presented in Table 2. None of the treatment failure secondary efficacy endpoints (ie, ETF, LCTF, and LPTF) was significantly different for the comparison of the two study groups. Only one PCR-confirmed LPTF $(1 \%)$ was reported in the AL group, which adequately responded to the second-line treatment of quinine and primaquine and corresponded to the MAD2O MSP1 haplotype. Although the mean parasite clearance time was not statistically significant between the study groups, the mean fever clearance times showed a significantly earlier response in the $A S+A Q$ group $(p=0.002)$. (Table 2).

Spontaneously reported adverse events were limited to epigastric burning sensation in $1(1 \%)$ patient in the AS+AQ group versus 14 (13.3\%) patients in the AL group $(p<0.001)$. No hospitalizations or deaths related to malaria or its complications, study treatments, adverse events, or any other cause occurred during the study.

\section{DISCUSSION}

To the best of researchers' knowledge, this is the first noninferiority trial comparing $A S+A Q$ to standard $A L$ therapy performed in the Colombian Pacific region. The primary efficacy endpoint-ie, a noninferiority margin of less than $5 \%$-was met.

Studies reporting similar crude $A C P R s$ when $A S+A Q$ and $A L$ are used have been published. A Cochrane meta-analysis of 50 studies $^{23}$ and a meta-analysis including 8 studies in Africa ${ }^{24}$ concluded that there is enough evidence to suggest that AL more effectively increases crude ACPR rates.

Regarding PCR-corrected ACPRs, Jansen et al performed a metaanalysis of 32 trials comparing the four WHO-recommended $\mathrm{ACT}^{25}$. In this multi-treatment, random-effects Bayesian analysis, $A S+A Q$ and $A L$ treatments had PCR-corrected ACPRs of $88.5 \%$ and $97.4 \%$, respectively. The authors explained that this difference was due to the inclusion of results from South Asian studies, where ACT drug resistance has been reported ${ }^{12,13}$. These results were not necessarily inferior, as proven through an odds ratio analysis for the PCR-corrected ACPR ${ }^{25}$.

On the other hand, Zwang et al demonstrated that PCR adjustment yields inconsistent ACPR rate results ${ }^{14}$. These authors performed an analysis of 26 studies $(n=5,942)$ comparing AS+AQ to other ACT in a pooled sub-Saharan African population. Crude ACPR rates of $78.3 \%$ for $A S+A Q$ and $83.2 \%$ for the other ACT were reported. However, when PCR adjustment was applied, the mean $(95 \% \mathrm{Cl})$ ACPR rates were superior: 93.9\% (93.2\%-94.5\%) for AS+AQ and 94.8\% (93.8\%-95.6\%) for the other ACT.

In Colombia, Osorio et al. have reported similar 100\% mean (95\% Cl: $89.1 \%-100 \%)$ PCR-adjusted ACPR rates for AS+AQ treatment in the Colombian Pacific region ${ }^{16}$. From the comparison of these data and the findings in this study, we infer that the crude and PCR-corrected ACPR rates found for adults treated with $A S+A Q$ in the Colombian
Pacific region are not different from those previously described. Even though AL is the standard treatment for uncomplicated $P$. falciparum malaria in Colombia, no literature discussing its ACPR rates in this country could be found in the literature reviewed.

No ETFs were found in either group. This can be explained by the rapid clinical improvement observed with all $\mathrm{ACTs}^{26}$. In the analysis performed by Zwang et al., the comparison of $A S+A Q$ with $A L$ yielded differences in the crude failure risks. The adjusted hazard ratio $(95 \%$ Cl) for AL was 0.79 (0.57-1.10), yielding a nonsignificant PCR-adjusted failure risk ${ }^{14}$. Neither LCTF nor LPTF were observed in the AS+AQ group, yielding a $0 \%$ failure rate.

The single LPTF corresponded to the MAD20 MSP1 haplotype, a native allele of the MSP1 gene, confirming a true failure rather than a reinfection. This polymorphic gene have been demonstrated as a marker of natural selection, rather than $P$. falciparum transmission dynamics, and its loci determine the variation in allele frequencies among populations ${ }^{27,28}$. In another regions of Colombia, it has been demonstrated that MAD20 haplotype with a 187-base-pair band is present in all of the samples analyzed, while the K1 and RO33 haplotypes were not found in these regions $\mathrm{s}^{29}$. Based on similar reports from Colombian regions ${ }^{30,31}$. Barrera et al concluded that MSP1 is not a good marker for genetic diversity studies in Colombia ${ }^{29}$.

Geometric mean parasitemia on day 1 was not statistically significantly different between $A S+A Q$ and $A L(p=0.76)$. When compared with the baseline geometric mean parasitemia, the $24 \mathrm{~h}$ mean change was statistically significant for either group $(p<0.001)$.

Compared with AL, mean fever clearance time was significantly lower $(p=0.002$ ) for $A S+A Q$. This significant fever clearance difference for the comparison of $A S+A Q$ and $A L$ have also been reported by Koram et al $(p=0.006)^{32}$. In this report, the proportion of patients treated with $A S+A Q$ that remained febrile at Day 2 was significantly lower when compared to those treated with AL, similar to a finding previously reported in another larger study ( $2.8 \%$ versus $6.3 \%$, respectively; $\mathrm{p}=0.001)^{14}$. Even though the clinical relevance of small but significant differences in fever clearance times is arguable, it seems evident that $A C T$ in genera ${ }^{26}$, and $A S+A Q$ in particular, offer a faster relief from the febrile state and the associated inflammatory response.

The correlation between parasitemia and fever clearance times has been verified in other reports ${ }^{14,33}$. The study by Zwang et al. found that parasitemia and fever percentages of patients treated with $\mathrm{AS}+\mathrm{AQ}$. were, respectively, $66.4 \%$ and $7.4 \%$ on day $1 ; 8.5 \%$ and $2.4 \%$ on day 2 ; $1.8 \%$ and $2.4 \%$ on day 3 ; and $0.6 \%$ on day 7 . This group demonstrated that parasitemia clearance time is significantly $(p=0.001)$ longer in patients with higher parasitemia at day 0 . Also, the risk of being parasitemic at day 3 was not different in patients treated with $A S+A Q$ or any other ACT ( $2.9 \%$ versus $2.6 \% ; p=0.48)^{14}$.

Whether the adverse events are truly attributable to the antimalarials or to malaria itself is still debatable. Some symptoms reported as adverse events are present at baseline and are exacerbated with antimalarial treatment. Gastrointestinal adverse events have been previously reported for both treatments. Compared to baseline, no significant differences were found between gastrointestinal spontaneously reported adverse events after starting either treatment. However, the proportion of patients presenting gastrointestinal adverse events was significantly higher $(p<0.001)$ in the AL treatment group. 
One of the limitations of this trial is that the efficacy profile of $A L$ is influenced by the wide between-individual variation of lumefantrine pharmacokinetics-absorption is poor when not taken with fatty foods ${ }^{34}$. On the other hand, inconsistencies in AS+AQ efficacy profiles worldwide are influenced by the previous use of amodiaquine in endemic countries, such as Colombia. These areas present with high rates of parasitological failures with ACPR, which reflect good immunity and dangerously poor antimalarial efficacy ${ }^{33}$.

The high level of recrudescence and reinfection rates present in the department of Choco further limit the extrapolation of these findings. PCR genotyping of polymorphic genes-such as the merozoite surface protein 1 and 2 (MSP1 and MSP2, respectively) precursor and the glutamate-rich protein (PF10_0344) genes-allow a reliable description of seasonal recrudescence patterns ${ }^{33}$, though many times the results are commonly missing or indeterminate ${ }^{22,29}$. Distinguishing recrudescence from reinfection can be a difficult task and there is no current consensus on how data should be analyzed ${ }^{22}$. The way the outcome measure is reported, the analyses performed, and the geographic location can partially explain the results variation ${ }^{23 ; 24}$. In everyday clinical practice, PCR genotyping increases the surveillance $\operatorname{costs}^{34}$, which is a major limitation in developing countries. Regarding safety limitations, the use of adverse events spontaneous reports introduces data production bias.

Besides a $10 \%$ failure rate, the WHO recommendations for changing first-line therapy should address other factors in further pharmacokinetic, in vitro, and molecular studies ${ }^{17}$. The noninferior efficacy demonstrated for AS+AQ compared to other ACT in general and to $A L$ in particular, pose a viable alternative for the treatment of $P$. falciparum malaria in the Chocó department. The easier administration schedule and the robust efficacy and safety profile also favor the use of $A S+A Q$ in this and similar settings. Being the most cost-effective treatment in prevention strategies, as it was previously demonstrated in sub-Saharan Africa ${ }^{15}$, treatment with $A S+A Q$ would grant savings in the treatment costs of uncomplicated $P$. falciparum malaria. Treatment of uncomplicated $P$. falciparum malaria with $A S+A Q$ also has high compliance rates, with or without health care staff supervision ${ }^{35}$.

In sum, the treatment of uncomplicated $P$. falciparum malaria with $A S+A Q$ was noninferior to the AL standard treatment. Caution should be exerted when extrapolating the study results, as these apply to the sui generis settings of the Chocó department. The efficacy and safety profiles of $A S+A Q$ make its use a plausible alternative treatment of uncomplicated $P$. falciparum malaria in the Colombian Pacific region.

\section{ACKNOWLEDGMENTS}

The authors would like to thank the CMSP for the advice given and the Consultant Experts: Silvia Blair Trujillo, PhD, from the Hemoparasites Laboratory, School of Medicine, University of Antioquia; Julio César Padilla, MD, Coordinator, Vector-transmitted Diseases Prevention and Control Group, Ministry of Social Protection; and Roberto Montoya, PhD, national professional for Transmissible Diseases in the Colombian representation of the PAHO. The authors would also like to acknowledge the medical writing assistance provided by Humberto López Castillo, MD, MSc, MEd, of PRIMO Scientific Corporation, Panama, Republic of Panama.

\section{CONFLICT OF INTEREST}

The authors declare that they have no actual or potential conflict of interests in the performance of this research. This study was made possible through an unrestricted educational grant from SANOFI. SANOFI was not involved in the patient enrollment, data analyses, or medical writing of this manuscript. Study investigators were independent and fully responsible for the study design, data analysis and presentation of the results.

\section{FINANCIAL SUPPORT}

This study was sponsored by SANOFI.

\section{ABSTRACT IN PORTUGUESE}

\section{Artesunato + amodiaquina versus artemether- limefantrina para o tratamento da malaria não complicada por Plamodium falciparum no Pacifico Colombiano: um estudo de não inferioridade}

Introdução: Na Colômbia não existem estudos publicados sobre o tratamento da malária não complicada por Plasmodium falciparum comparando as terapias combinadas com artemisinina. Destarte, quer se demonstrar a não inferioridade dos perfis de eficácia/segurança dos tratamentos com artesunato+amodiaquina versus artemeter-lumefantrina. Métodos: Foi realizado um estudo clínico de não inferioridade $(\Delta \leq 5 \%)$, aleatório, controlado, aberto, em adultos com malária não complicada por $P$. falciparum usando o desenho validado de 28 dias e os desenhos validados/definidos pela Organização Mundial da Saúde. Os pacientes foram aleatorizados (1:1) para ambos artesunato+amodiaquina ou artemeter-lumefantrina orais. Critérios primários de eficácia: resposta clínica e parasitológica adequada; Criterios de eficácia secundários: as falhas de tratamento definidos pela Organização Mundial da Saúde. A segurança: avaliada através de eventos adversos. Resultados: Foram incursos 105 pacientes em cada grupo: zero observações censuradas. As taxas médias da resposta clínica e parasitológica adequada (95\% IC - intervalo de confiança): $100 \%$ para artesunato+amodiaquina e $99 \%$ para artemeter-lumefantrina; atingiuse o critério de não inferioridade $(\Delta=1.7 \%)$. Houve uma falha terapêutica parasitológica tardia (1\%; grupo artemeter-lumefantrina), caracterizada mediante reação em cadeia da polimerase como o alelo MAD20 MSP1. Tempo de remissão da febre (grupo artesunato+amodiaquina), foi significativamente mais curto $(p=0.002)$. Dor abdominal, para artesunato+amodiaquina e artemeter-lumefantrina, respectivamente, $1.9 \%$ e $3.8 \%(p=0.68)$ na linha de base, $1 \%$ e $13.3 \%$ pós-tratamento $(p<0.001)$. Conclusões: 0 tratamento com artesunato+amodiaquina da malária não complicada por $P$. falciparum é não inferior ao tratamento normal com artemeter-lumefantrina. Os perfis de eficácia/ segurança justificam estudos adicionais nesta e outras populações semelhantes.

Palavras-chaves: Combinação de artesunato-amodiaquina. Combinação de artemeter-lumefantrina. Eficácia. Segurança. Malária-falciparum. Colômbia.

\section{REFERENCES}

1. World Helath Organization Global Malaria Programme. WHO Malaria Report: 2010. Geneva: WHO Press; 2011

2. Moyano M, Mendez F. Erythrocyte defects and parasitemia density in patients with Plasmodium falciparum malaria in Buenaventura, Colombia [in Spanish] Rev Panam Salud Publica 2005; 18:25-32.

3. Rodríguez JC, Uribe GÁ, Araújo RM, Narváez PC, Valencia SH. Epidemiology and control of malaria in Colombia. Mem Inst Oswaldo Cruz 2011; 106 (supl I):114-122.

4. Censo General 2005. Nivel Nacional [in Spanish]. Bogotá, Colombia: Departamento Administrativo Nacional de Estadística, 2005. 
5. Ochoa J, Osorio L. Epidemiology of urban malaria in Quibdó, Chocó [in Spanish]. Biomedica 2006; 26:278-285.

6. Valero-Bernal MV. Malaria in Colombia: retrospective glance during the past 40 years. Rev Salud Publica (Bogotá) 2006; 8:141-149.

7. Bray PG, Ward SA, O'Neill PM. Quinolones and artemisinin: chemistry, biology and history. In: Sullivan DJ, Krishna S, editors. Malaria: drugs, disease and post-genomic biology. Berlin, Germany: Springer-Verlag; 2005. p. 3-98.

8. González IJ, Varela RE, Murillo C, Ferro BE, Salas J, Giraldo LE, et al. Polymorphisms in cg2 and pfcrt genes and resistance to chloroquine and other antimalarials in vitro in Plasmodium falciparum isolates from Colombia. Trans R Soc Trop Med Hyg 2003; 97:318-324.

9. Samudio F, Santamaria AM, Obaldia III N, Pascale JM, Bayard V, Calzada JE. Prevalence of Plasmodium falciparum mutations associated with antimalarial drug resistance during an epidemic in Kuna Yala, Panama, Central America. Am J Trop Med Hyg 2005; 73:839-841.

10. Leal O, Leal EA, Borges Júnior FR, Paez ML, Teodosio S, Tavares-Neto J. Clinicalparasitological response to treatment with quinine associated to doxycycline in uncomplicated falciparum malaria [in Portuguese]. Rev Soc Bras Med Trop 2003; 36:751-754.

11. World Health Organization. Guidelines for the Treatment of Malaria. Geneva: WHO Press; 2006.

12. Alker AP, Lim P, Sem R, Shah NK, Yi P, Bouth DM, et al. Pfmdr1 and in vivo resistance to artesunate-mefloquine in falciparum malaria on the Cambodian-Thai border. Am J Trop Med Hyg 2007; 76:641-647.

13. Dondorp AM, Nosten F, Yi P, Das D, Phyo AP, Tarning J, et al. Artemisinin resistance in Plasmodium falciparum malaria. N Engl J Med 2009; 361:455-467.

14. Zwang J, Olliaro P, Barennes $\mathrm{H}$, Bonnet $\mathrm{M}$, Brasseur $\mathrm{P}$, Bukirwa $\mathrm{H}$, et al. Efficacy of artesunate-amodiaquine for treating uncomplicated falciparum malaria in subSaharan Africa: a multi-centre analysis. Malar J 2009; 8:203.

15. Conteh L, Sicuri E, Manzi F, Hutton G, Obonyo B, Tediosi F, et al. The costeffectiveness of intermittent preventive treatment for malaria in infants in SubSaharan Africa. PLoS One 2010; 5:e10313.

16. Osorio L, Gonzalez I, Olliaro P, Taylor WR. Artemisinin-based combination therapy for uncomplicated Plasmodium falciparum malaria in Colombia. Malar J 2007; 6:25.

17. World Health Organization. Methods for Surveillance of Antimalarial Drug Efficacy. France: WHO Press; 2009.

18. Amazon Network for the Surveillance of Antimalarial Drug Resistance. Amazon Malaria Initiative (RAVEDRA-AMI). Practical Guide for in vivo Antimalarial DrugEfficacy Studies in the Americas. PAHO Publication OPS/DPC/CD/240/03. [Cited 2011 January 8]. Available from: http://www.paho.org/english/ad/dpc/cd/guiapractica.pdf.

19. Center for Drug Evaluation and Research; Food and Drug Administration. Guidance for Industry. Malaria: Developing Drug and Nonvaccine Biological Products for Treatment and Prophylaxis. Rockville, MD: U.S. Department of Health and Human Services; 2007. [Cited 2011 January 8]. Available from: http://www.fda. gov/downloads/Drugs/GuidanceComplianceRegulatoryInformation/Guidances/ ucm071951.pdf.
20. Dasgupta A, Lawson KA, Wilson JP. Evaluating equivalence and noninferiority trials. Am J Health Syst Pharm 2010; 67:1337-1343.

21. Stepniewska K, White NJ. Some considerations in the design and interpretation of antimalarial drug trials in uncomplicated falciparum malaria. Malar J 2006; 5:127.

22. World Medical Association. WMA Declaration of Helsinki - Ethical Principles for Medical Research Involving Human Subjects. 2008. Seoul, Korea, World Medical Association. [Cited 2011 January 8]. Available from: http://www.wma.net/ en/30publications/10policies/b3/index.html.

23. Sinclair D, Zani B, Donegan S, Olliaro P, Garner P. Artemisinin-based combination therapy for treating uncomplicated malaria. Cochrane Database Syst Rev 2009; CD007483.

24. Taylor-Robinson D, Jones K, Garner P. Malaria: uncomplicated, caused by Plasmodium falciparum. Clin Evid 2007; [Cited 2011 August 8]. Available from: http://www.ncbi.nlm.nih.gov/pmc/articles/PMC2907983/?tool=pubmed/.

25. Jansen FH, Lesaffre E, Penali LK, Zattera MJ, Die-Kakou H, Bissagnene E. Assessment of the relative advantage of various artesunate-based combination therapies by a multi-treatment Bayesian random-effects meta-analysis. Am J Trop Med Hyg 2007; 77:1005-1009.

26. Balint GA. Artemisinin and its derivatives: an important new class of antimalarial agents. Pharmacol Ther 2001; 90:261-265.

27. Ferreira MU. The merozoite surface protein-1 (MSP-1) of Plasmodium falciparum: allelic diversity and immune recognition [abstract]. Rev Soc Bras Med Trop 1998; 31:395-397.

28. Pereira $\mathrm{FJ}$, Cordeiro JA, Hoffmann EH, Ferreira MU. Genetic diversity and differentiation in natural Plasmodium falciparum populations inferred by molecular typing of the merozoite surface proteins 1 and 2. Rev Soc Bras Med Trop 2002; 35:527-530.

29. Barrera SM, Pérez MA, Knudson A, Nicholls RS, Guerra AP. Genotypic survery of Plasmodium falciparum based on the msp1, msp2 and glurp genes by multiplex PCR [in Spanish]. Biomedica 2010; 30:530-538.

30. Guerra AP, Knudson A, Nicholls RS, Galindo JA, Ravid Z, Rahirant S, et al. Genotyping of the Plasmodium falciparum msp1 (block 2) and dhfr (codon 108) genes in field samples collected in four endemic Colombian localities [in Spanish]. Biomedica 2006; 26:101-112.

31. Montoya L, Maestre A, Carmona J, Lopes D, Rosário V, Blair S. Plasmodium falciparum: diversity studies of isolates from two Colombian regions with different endemicity. Exp Parasitol 2003;104:14-19.

32. Koram KA, Abuaku B, Duah N, Quashie N. Comparative efficacy of antimalarial drugs including ACTs in the treatment of uncomplicated malaria among children under 5 years in Ghana. Acta Trop 2005; 95:194-203.

33. White NJ. The assessment of antimalarial drug efficacy. Trends Parasitol 2002; 18:458-464.

34. World Health Organization. Global report on antimalarial drug efficacy and drug resistance: 2000-2010. Geneva, Switzerland: WHO Press; 2010.

35. Asante KP, Owusu R, Dosoo D, Awini E, Adjei G, Amenga Etego S, et al. Adherence to artesunate-amodiaquine therapy for uncomplicated malaria in rural Ghana: a randomised trial of supervised versus unsupervised drug administration. J Trop Med 2009; 2009:529-583. 